\title{
Design of a Miniature Dual-Band Patch Antenna Based on Meta-Materials for 5G and Wi-Fi Applications ${ }^{+}$
}

\author{
Yamina Belhadef ${ }^{1, *}$, Fatima Zohra Moussa ${ }^{2}$ and Souheyla Ferouani ${ }^{3} \mathbb{D}$ \\ 1 LTT Laboratory of Tlemcen, Department of Telecommunications, Abou-Bekr Belkaïd University, BP 230, \\ Pôle Chetouane, Tlemcen 13000, Algeria \\ 2 SSL Laboratory of Ain Temouchent, Department of Electronic and Telecommunications, \\ Belhadj Bouchaib University, BP 284, Route de Sidi Bel Abbes, Ain Témouchent 46000, Algeria; \\ moussafatima12@hotmail.com \\ 3 LTT Laboratory of Tlemcen, Department of Electronic and Telecommunications, Belhadj Bouchaib University, \\ BP 284, Route de Sidi Bel Abbes, Ain Témouchent 46000, Algeria; souhilaferouani@gmail.com \\ * Correspondence: belhadef_y@yahoo.fr \\ + Presented at the 1st International Conference on Computational Engineering and Intelligent Systems, Online, \\ 10-12 December 2021.
}

check for updates

Citation: Belhadef, Y.; Moussa, F.Z.; Ferouani, S. Design of a Miniature Dual-Band Patch Antenna Based on Meta-Materials for 5G and Wi-Fi Applications. Eng. Proc. 2022, 14, 13. https: / / doi.org/10.3390/engproc 2022014013

Academic Editors:

Adbelmadjid Recioui,

Hamid Bentarzi and Fatma

Zohra Dekhandji

Published: 11 February 2022

Publisher's Note: MDPI stays neutral with regard to jurisdictional claims in published maps and institutional affiliations.

Copyright: (C) 2022 by the authors. Licensee MDPI, Basel, Switzerland. This article is an open access article distributed under the terms and conditions of the Creative Commons Attribution (CC BY) license (https:// creativecommons.org/licenses/by/ $4.0 /)$.

\begin{abstract}
Our work consists of designing a dual-band planar antenna based on meta-materials for 5G applications. We propose a design approach consisting of a deposited patch antenna on an FR-4 type monolayer substrate placed above the CSRR cells based on the meta-materials working in millimeter wave. Thereafter, we will do a parametric study to extract the various parameters that influence its electromagnetic behavior. The studied and designed antenna aims to be used for 5G phone applications in the frequency band 3.3-3.8 GHz and Wi-Fi. The design is carried out by CST Microwave Studio software.
\end{abstract}

Keywords: design; patch antenna; bi-band antenna; miniature antenna; meta-materials; 5G; Wi-Fi; CST Microwave Studio

\section{Introduction}

The commercial use of 5G has arrived to meet the growing demands for low latency, big capacity, and ubiquitous mobile access, and will play a key role in connecting and enabling services. 5G must address, in addition to an increase in traffic volume, the challenge of connecting billions of devices to heterogeneous service needs [1]. 5G networks are expected to supply a lot of improvements [2].

The antenna is an essential element in 5G networks; however, it always occupies a higher volume in the communication chain, making it difficult to implement in small areas. Its miniaturization has become essential for an optimal design. Many antenna miniaturization techniques exist, and all go through a compromise between size and performance (bandwidth and/or radiation yield) [3], such as charging by passive elements, short circuit application, slots insertion, and use of a dielectric substrate of very high permittivity and meta-materials, etc.

Most materials found in nature (e.g., dielectrics) have positive constitutive parameters $(\varepsilon>0$ and $\mu>0)$. For this reason, they are called doubly positive materials (DPS). Materials with negative permittivity and positive permeability $(\varepsilon<0$ and $\mu>0)$ are called epsilon-negative materials (ENG), whose characteristics are presented by plasmas at certain frequencies [4]. On the other hand, materials with positive permittivity and negative permeability $(\varepsilon>0$ and $\mu<0)$ are known as mu-negative materials (MNG), and ferrites exhibit this behavior at certain frequencies [5]. Materials that have negative constitutive parameters $(\varepsilon<0$ and $\mu<0)$ are called doubly negative materials (DNG), or meta-materials. Until now, these materials have not been found in nature and they are obtained artificially. 
Meta-materials have attracted great attention in recent years due to their unusual electromagnetic properties and their ability to guide and control electromagnetic waves where natural materials cannot [6]. The meta-materials used in the antennas field offer advantages such as reduction in weight and bulk, which is beneficial for their integration into electronic systems such as telecommunications systems in general, and telephone systems for the fifth generation (5G) in particular. In addition, the use of the latter aims to improve its characteristics in terms of resonance frequency (to have multi-band structures or rejected bands) and to make them reconfigurable, as well as for improved bandwidth, gain, directivity, mutual coupling minimization in an antenna array, polarization, and radiation pattern [7-9].

\section{Design of a Patch Antenna for 5G}

The geometry of the initial antenna is shown in Figure 1. This structure consists of a radiating element with length $\mathrm{Lp}$ and width $\mathrm{Wp}$, with notches, fed by a microstrip line. It is deposited on an FR-4 type dielectric substrate with dielectric permittivity $\varepsilon r=4.3$, of dimensions Ls and Ws and thickness $h$. The ground plane covers the substrate's whole rear face. Table 1 gives the dimensions of the initial antenna with notches using the given equations in [10-12].
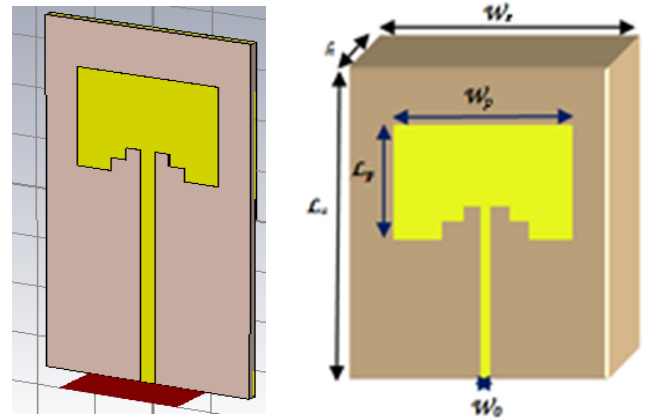

Figure 1. Geometry of the initial antenna.

Table 1. Dimensions of the initial antenna.

\begin{tabular}{cc}
\hline Dimensions & Size $(\mathbf{m m})$ \\
\hline $\mathrm{L}_{\mathrm{s}}$ & 70.68 \\
$\mathrm{~W}_{\mathrm{s}}$ & 34.9 \\
$\mathrm{~h}$ & 1.595 \\
$\mathrm{~L}_{\mathrm{p}}$ & 19.722 \\
$\mathrm{~W}_{\mathrm{p}}$ & 24 \\
$\mathrm{~W}_{0}$ & 2.5 \\
\hline
\end{tabular}

Figure $2 \mathrm{a}, \mathrm{b}$ represents, respectively, the return loss, the stationary wave rate VSWR, and the gain of the initial antenna.



(a)

Figure 2. Cont. 


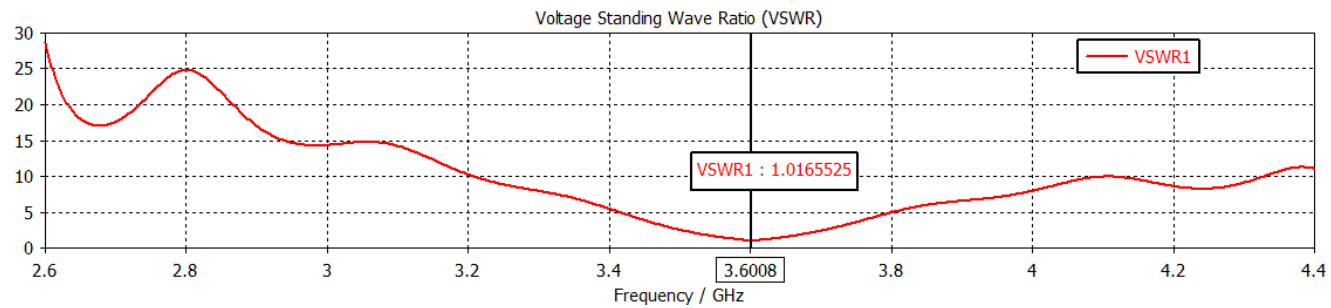

(b)

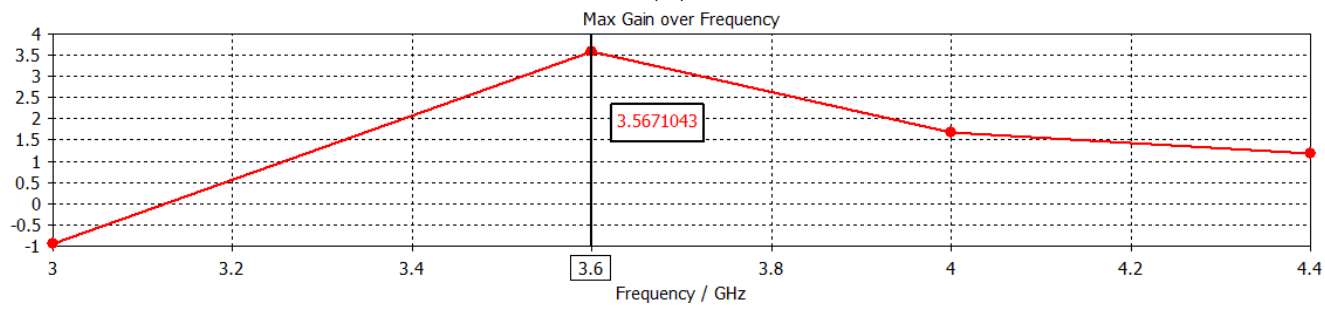

(c)

Figure 2. (a) Return loss. (b) Stationary wave rate. (c) Antenna gain.

Figure 2a shows that the adaptation is well-realized since the return loss S11 attains a level close to $-41.86 \mathrm{~dB}$ at the resonant frequency $3.6 \mathrm{GHz}$, so the reflection at the antenna input is zero. We have also presented the stationary wave rate, which we notice is between 1 and 2 in the theoretical frequency band $3.53-3.67 \mathrm{GHz}$, which shows a good impedance match between the antenna and the feed line. The bandwidth is order $3.88 \%$. The antenna gain is around $3.567 \mathrm{~dB}$ at the resonance frequency $3.6 \mathrm{GHz}$.

Figure $3 a-c$ represents, respectively, the polar radiation patterns, in $2 \mathrm{D}$ and $3 \mathrm{D}$, of the antenna at the resonant frequency $3.6 \mathrm{GHz}$.

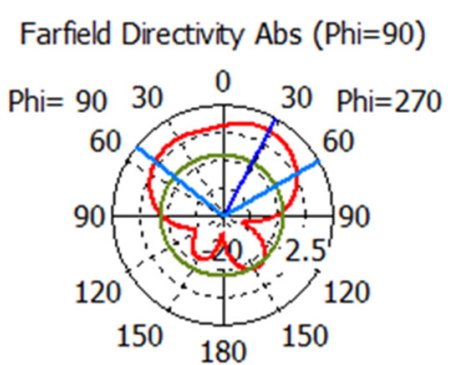

(a)

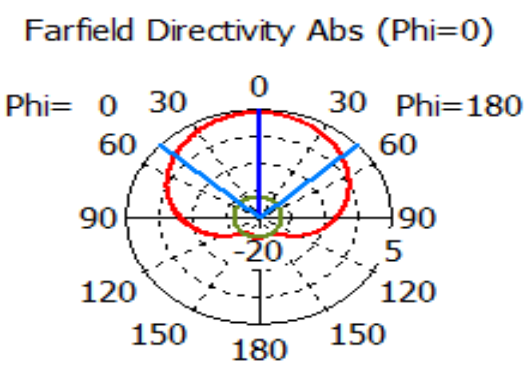

(b)



(c)

Figure 3. (a) Radiation pattern in 2D, plan H. (b) Radiation pattern in 2D, plan E. (c) Radiation pattern in $3 \mathrm{D}$.

We notice that the exhibit antenna has almost omnidirectional radiation in the E-plane $\left(\varphi=0^{\circ}\right)$ and in the H-plane $\left(\varphi=90^{\circ}\right)$. These plots are verified on the radiation pattern plot in 3D.

\section{Design of the CSRR Cell for 5G}

The two-dimensional periodic structure of a complementary split-ring resonator (RAFC) is shown in Figure 4. The CSRR (complementary split-ring resonator) is placed on a lossy FR-4 type substrate characterized by a permittivity of 4.3 , with a thickness of $1.56 \mathrm{~mm}$. For the studied square RAFC, the external slot ring's external side is equal to $(\mathrm{A}=4.9 \mathrm{~mm})$, and the internal slot ring's external side is equal to $(\mathrm{B}=4 \mathrm{~mm})$. The two rings are concentric and spaced at $0.12 \mathrm{~mm}$. Each ring is $0.33 \mathrm{~mm}$ wide, with a cut in the side of each ring presenting a gap of $\mathrm{g}=0.59 \mathrm{~mm}$. 


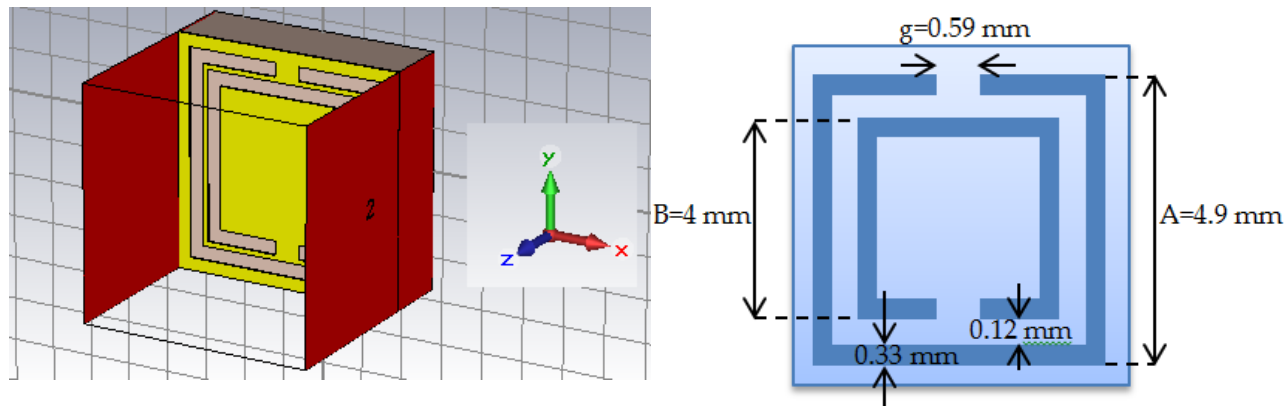

Figure 4. CSRR cell at the resonant frequency 3.6 GHz.

Figure 5 represents the modulus in $\mathrm{dB}$ of the return loss (S11) and transmission coefficient (S21) of the CSRR cell obtained by CST MWS software.

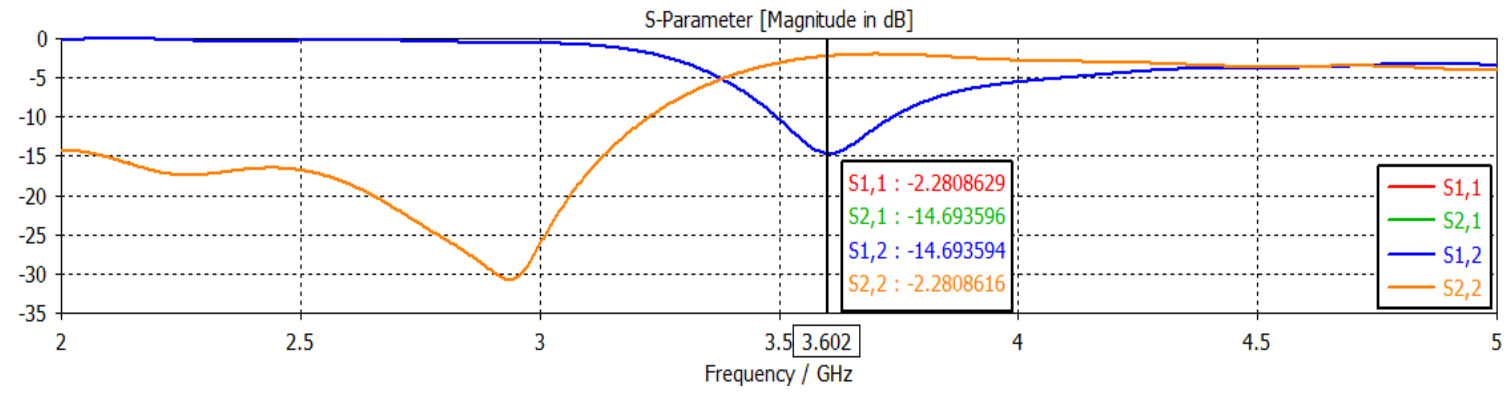

Figure 5. Transmission coefficient and return loss of the CSRR cell.

From the presented results in Figure 5, it can be seen that:

- $\quad$ The return loss $\mathrm{S} 11$ modulus presents a resonance at $3.602 \mathrm{GHz}$ with a reflection of $-2.28 \mathrm{~dB}$.

- $\quad$ The transmission coefficient S21 modulus goes down to a value of $-14.69 \mathrm{~dB}$ at the resonant frequency $3.602 \mathrm{GHz}$.

\section{Design of a Dual-Band Antenna Based on Meta-Materials}

Figure 6 presents three proposals for the radiating element of the initial antenna combined with CSRR cells. We have modified the number of CSRR cells on the radiating element in order to see their influences on the adaptation, while keeping the other antenna parameters unchanged.

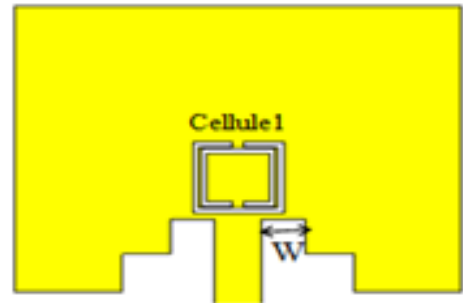

(a)

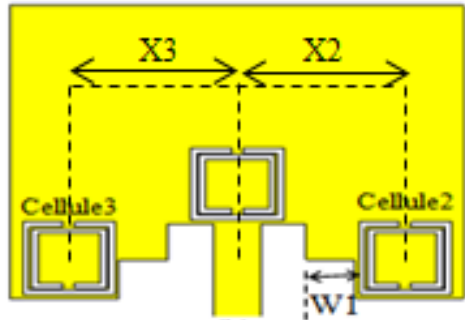

(b)

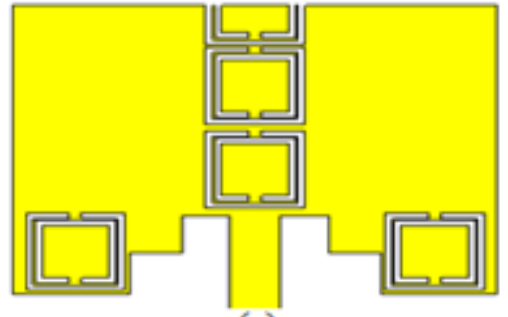

(c)

Figure 6. (a) Radiating element plus a CSRR cell. (b) Radiating element plus three CSRR cells. (c) Radiating element plus several CSRR cells.

Figure 7 represents, respectively, the return losses for the three structures proposed previously. 


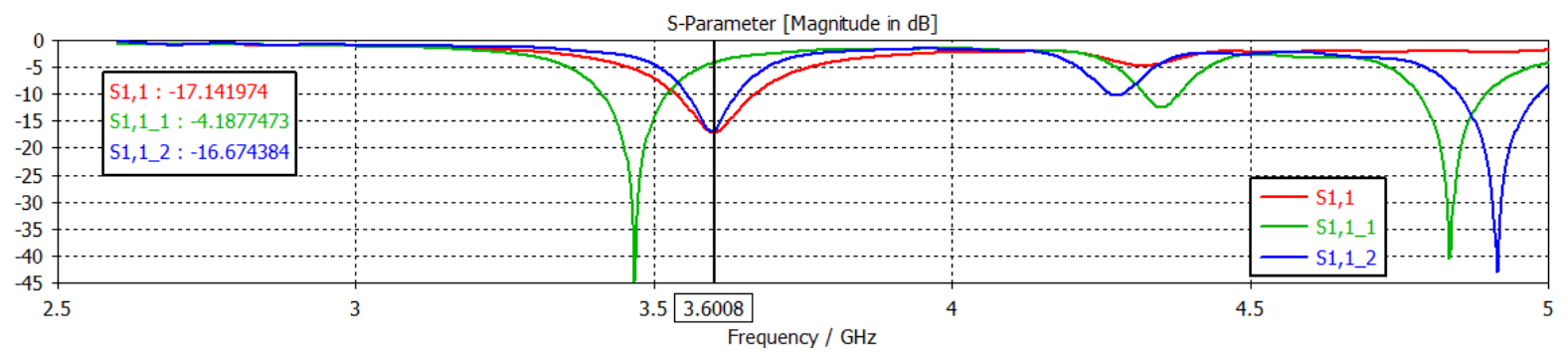

Figure 7. Return losses for the three structures, respectively.

The notes that can be extracted from these curves are:

The simulation result for the first structure of a CSRR cell (Figure 6a) gives a monofrequency operation with a return loss of $-17.14 \mathrm{~dB}$ at the resonant frequency $3.6 \mathrm{GHz}$. For the second three-cell structure (Figure $6 \mathrm{~b}$ ), the antenna exhibits tri-band operation at the resonant frequencies $3.466 \mathrm{GHz}, 4.352 \mathrm{GHz}$, and $4.834 \mathrm{GHz}$, with return loss levels below $-44.73 \mathrm{~dB},-12.55 \mathrm{~dB}$, and $-40.45 \mathrm{~dB}$, respectively.

The design result for the last structure, where we inserted several CSRR cells on the radiating element (Figure $6 \mathrm{c}$ ), shows that the reflected power contains three resonant frequencies-3.596 GHz, 4.275 GHz, and 4.91 GHz-with levels equal to - $16.86 \mathrm{~dB}$, $10.29 \mathrm{~dB}$, and $-43 \mathrm{~dB}$, respectively.

Accordingly, the best structure one can choose to complete our study is the third structure because of its gives multi-band operation where the first peak of the return loss resonates almost at the desired resonance frequency of $3.6 \mathrm{GHz}$.

To show the effect of the different geometrical parameters of the chosen structure (the widths $\mathrm{W}$ and $\mathrm{W} 1$ of the notches, the location $\mathrm{X} 2$ of the second CSRR cell, the location X3 of the third CSRR cell, and the length Ls of the ground plane and of the substrate) on the antenna characteristics (Figure $5 c$ ), we carried out a parametric study to observe the influence of these elements on the antenna-matching.

\subsection{Variation in Notch Width $W$}

The curves shown in Figure 8 present a dual-band operation in which we observe two resonance frequencies: the first is at $3.59 \mathrm{GHz}$ and the second is around $4.9 \mathrm{GHz}$.

We notice that the level of the return loss is inversely proportional to the notch width W for the first peak, where the decrease of the width W leads to an increase of the S11 level. For the second peak, the return loss increases when $W$ increases. The best obtained result corresponds to $\mathrm{W}=1.6 \mathrm{~mm}$, such that the return loss reaches a value lower than $-34.73 \mathrm{~dB}$ at the frequency $3.5912 \mathrm{GHz}$.

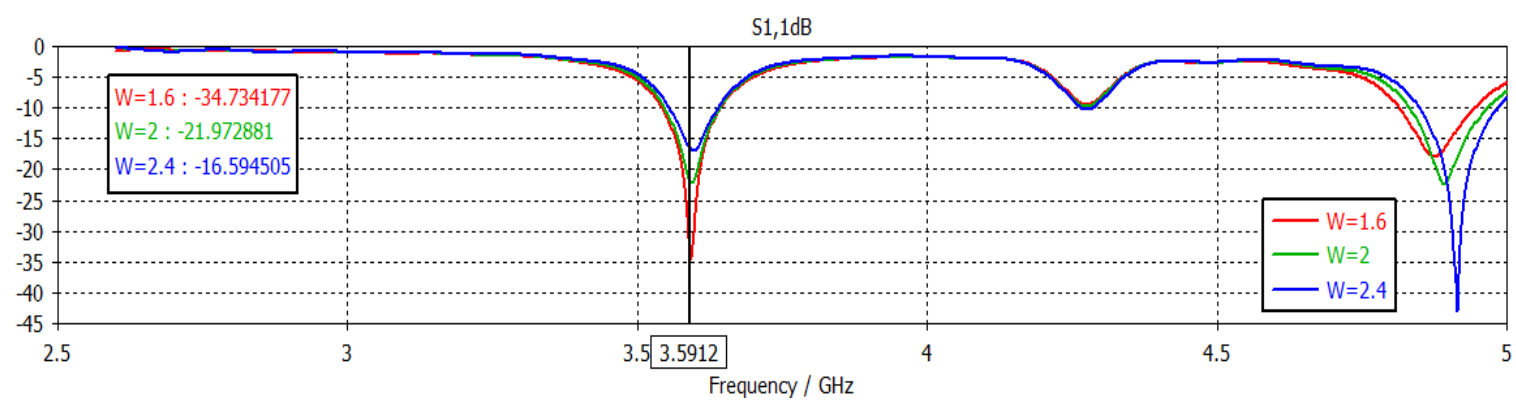

Figure 8. Influence of the notch width $\mathrm{W}$ on adaptation.

\subsection{Variation of the Notch Width W1}

The variation of the width W1 of the simulated antenna by CST MWS by fixing the width $\mathrm{W}$ to $1.6 \mathrm{~mm}$ is shown in Figure 9. This geometry appears as the most promising for $\mathrm{W} 1=2.3 \mathrm{~mm}$, where the amplitude of the reflected power is less than $-47.66 \mathrm{~dB}$ at the 
desired frequency $3.5864 \mathrm{GHz}$. This variation provides a particular improvement in the adaptation of the antenna compared to the previous study.

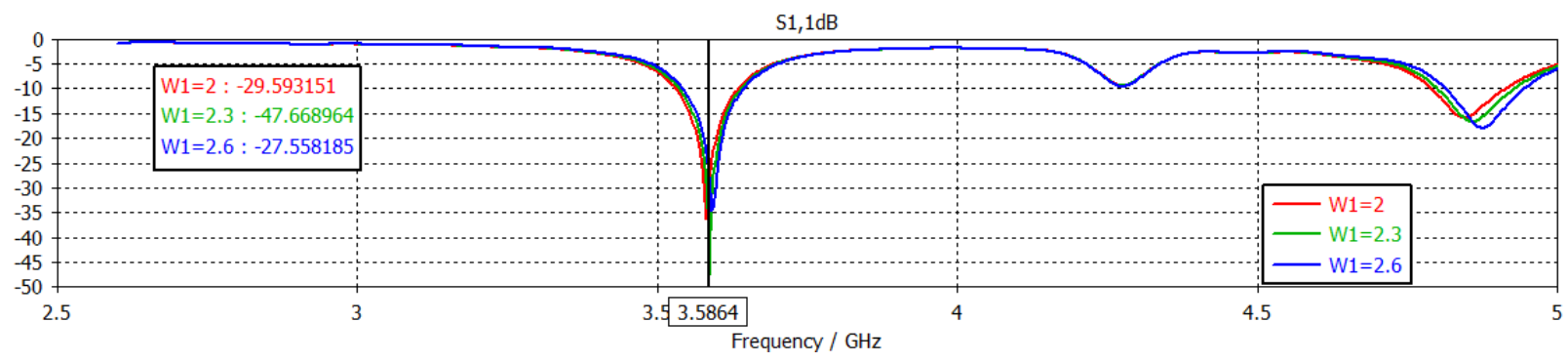

Figure 9. Influence of the notch width $\mathrm{W} 1$ on adaptation.

\subsection{Variation of the X2 Distance of Second CSRR Cell}

From the obtained results, we can visualize that the increase of the return loss level is inversely proportional to the $\mathrm{X} 2$ distance. We also observe a slight improvement in the resonance frequency that becomes to equal $3.5977 \mathrm{GHz}$, almost equal to the desired resonance frequency $3.6 \mathrm{GHz}$.

\subsection{Variation of the X3 Distance of the Third CSRR Cell}

In this phase, we made a slight variation to this distance by placing $X 2$ at $8.29 \mathrm{~mm}$. Figure 10 shows us that the curves are almost identical in the shape, but they have different levels of the return loss S11.

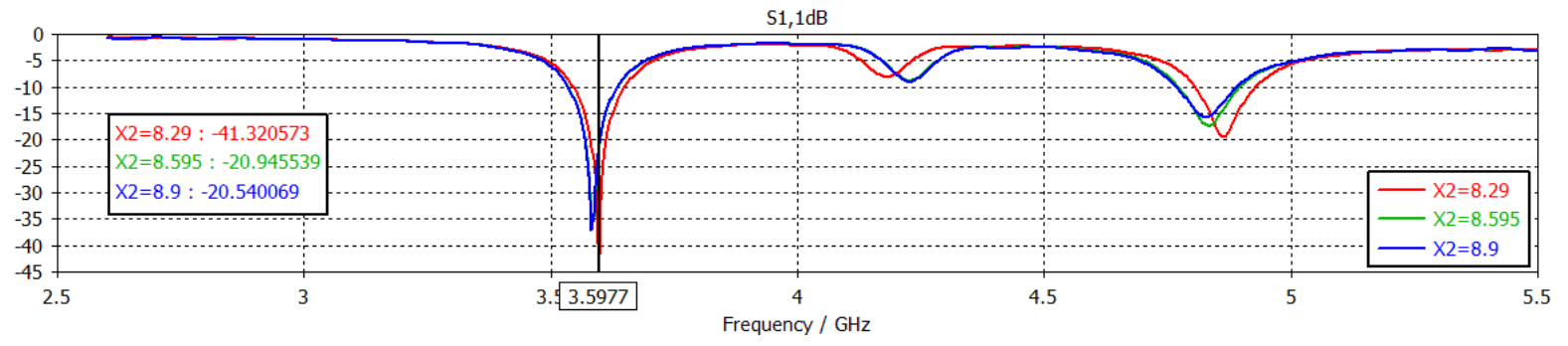

Figure 10. Influence of the $\mathrm{X} 2$ distance on adaptation.

\subsection{Variation of the Length Ls of the Ground Plane and the Substrate}

Now, we are interested in the influence of the length Ls of the ground plane and the substrate on the adaptation by fixing $\mathrm{X} 3$ at $8.29 \mathrm{~mm}$ (Figure 11).

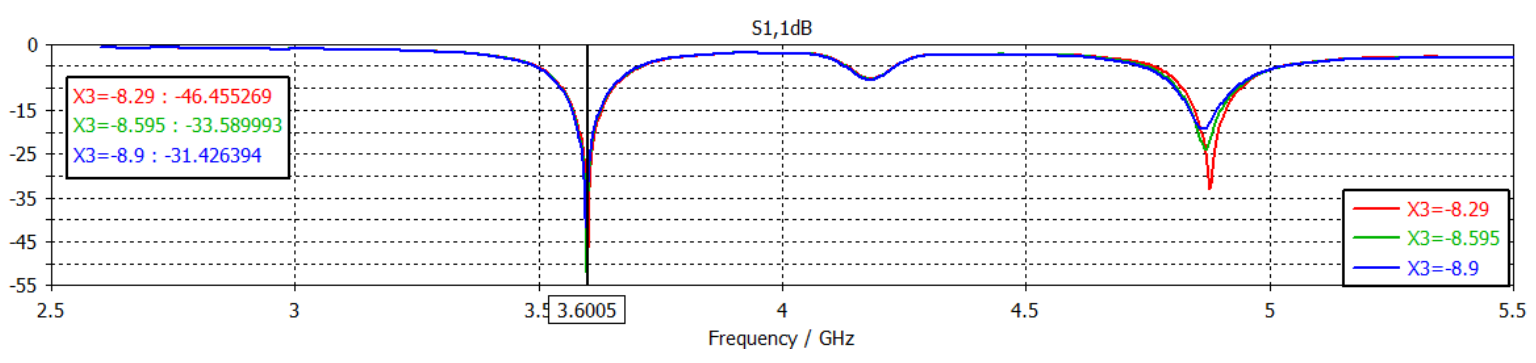

Figure 11. Influence of the $\mathrm{X} 3$ distance on adaptation.

According to Figure 12, the curves have identical shapes with different levels of the return loss. It is noticed that the reflection coefficient is inversely proportional to the length Ls of the ground plane and the substrate. The best result recorded corresponds to the length $\mathrm{Ls}=65.68 \mathrm{~mm}$. 


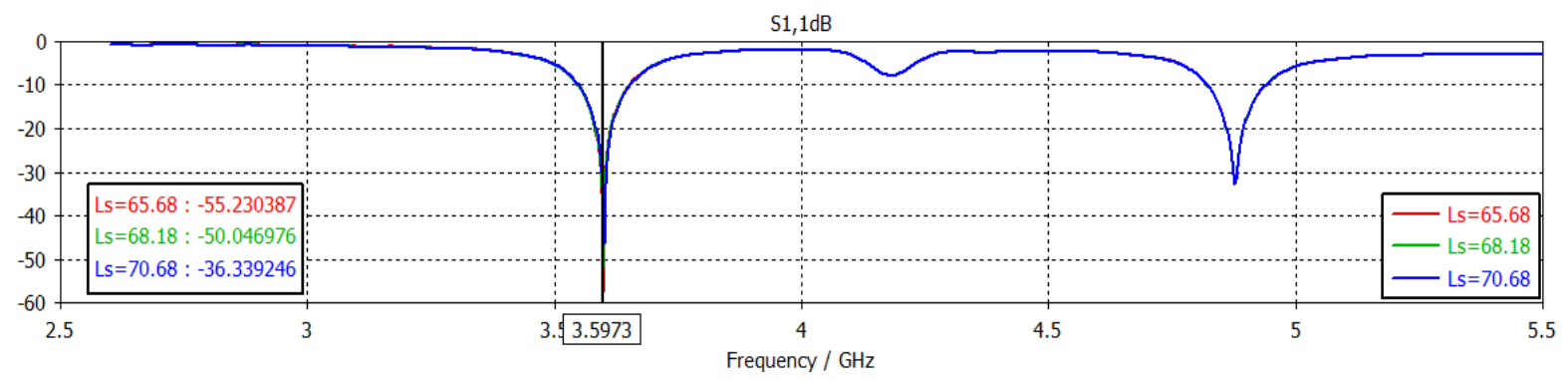

Figure 12. Influence of the length Ls on adaptation.

In Figure 13a-c, respectively, we represent the return loss, the VSWR, and the gain of the final dual-band antenna according to the last parametric study of the length Ls.

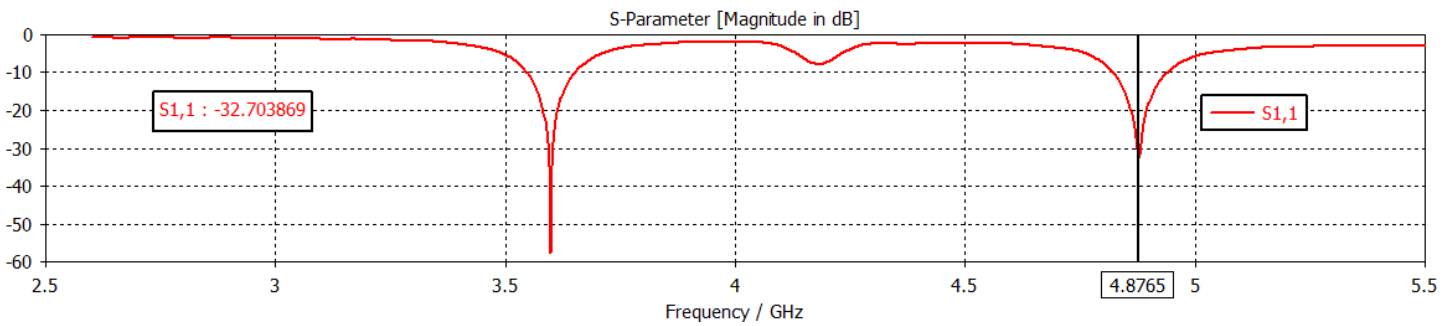

(a)

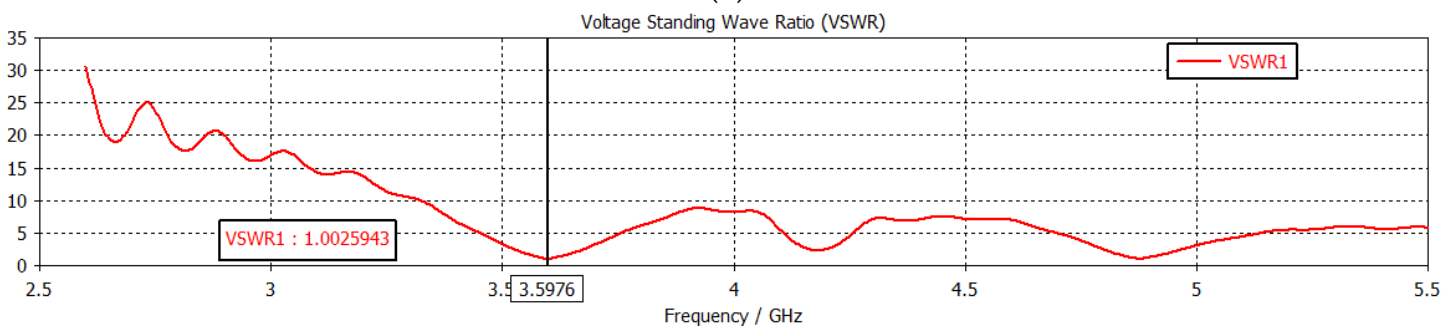

(b)

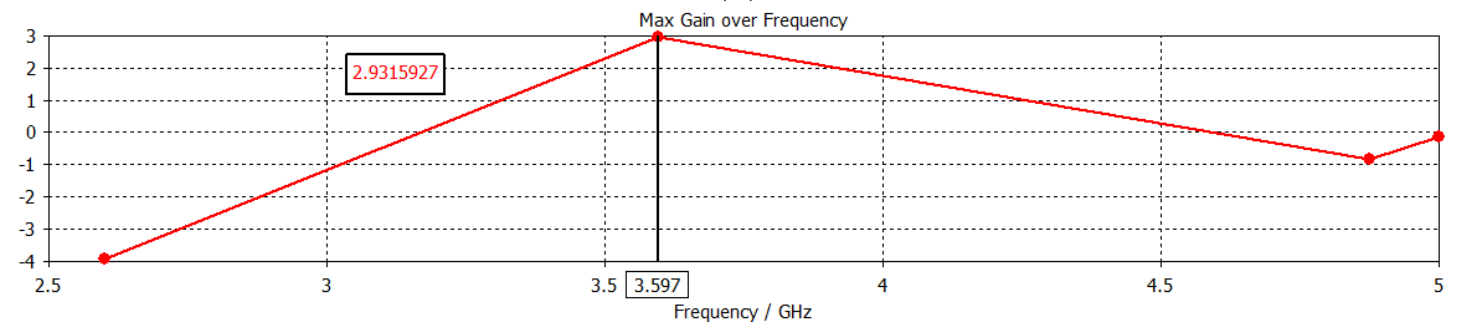

(c)

Figure 13. (a) Return loss. (b) Stationary wave rate. (c) Antenna gain.

According to the last study that we carried out and for Ls equal to $65.68 \mathrm{~mm}$, the simulation results bring back a perfect adaptation to the resonance frequencies for a dualband antenna. From Figure 13a, it can be said that the reflected power at the antenna input is zero since the two peaks reach values less than $-55.23 \mathrm{~dB}$ and $-32.70 \mathrm{~dB}$ at the frequencies $3.597 \mathrm{GHz}$ and $4.876 \mathrm{GHz}$, respectively, according to the $5 \mathrm{G}$ and Wi-Fi systems. This result is very encouraging when comparing it with the initial result we recorded in our main antenna (Figure 1) with a miniaturization rate of around $07.07 \%$.

We have also presented the stationary wave rate, which is of the order of one for each of the two resonance frequencies, which gives a good impedance match between the antenna and the feed line. The bandwidths are of the order of $101.5 \mathrm{MHz}$ and $116 \mathrm{MHz}$ for the two resonance frequencies, respectively. The antenna gain is around $2.93 \mathrm{~dB}$ at the $3.597 \mathrm{GHz}$ resonance frequency. 
Moreover, we find that the percentage of miniaturization of $07.07 \%$ is the best since it presents a perfect adaptation and a very satisfactory frequency band.

\section{Conclusions}

During this work, we have studied and designed a rectangular patch antenna intended for the new generation of mobile telephony, the fifth generation (5G). To learn about the effect of meta-material technology on printed antennas, we have inserted CSRR cells on the proposed rectangular patch antenna. The new geometry simulated by the CST Microwave Studio software presents a miniature bi-band antenna based on meta-materials according to the two $5 \mathrm{G}$ and Wi-Fi systems.

Author Contributions: All authors contributed to this proceeding paper article. All authors have read and agreed to the published version of the manuscript.

Funding: This research received no external funding.

Informed Consent Statement: Informed consent was obtained from all subjects involved in the study.

Data Availability Statement: Data sharing not applicable.

Conflicts of Interest: The authors declare no conflict of interest.

\section{References}

1. Hajri, S.E. L'amélioration des Performances des Systèmes sans fil 5G Par Groupements Adaptatifs des Utilisateurs. Ph.D. Thesis, Université Paris-Saclay, Paris, France, 2018.

2. Borhani Kakhki, M. Antennes à Formation de Faisceaux en Ondes Millimétriques Basées sur des Métamatériaux Pour les Applications 5G. Ph.D. Thesis, Université du Québec, Quebec City, QC, USA, 2020.

3. Kristou, N. Étude et Conception de Métamatériaux Accordables Pour la Miniaturisation D’antennes aux Fréquences Microondes. Ph.D. Thesis, Universite de Rennes 1, Paris, France, 8 June 2018.

4. Pendry, J.B.; Holden, A.J.; Robbins, D.J.; Stewart, W.J. Extremely Low Frequency Plasmons in Metallic Meso structures. Phys. Rev. Lett. 1996, 25, 4773-4776. [CrossRef] [PubMed]

5. Krowne, C.M.; Zhang, Y. Physics of Negative Refraction and Negative Index Materials: Optical and Electronic Aspects and Diversified Approaches, 1st ed.; Springer: Berlin/Heidelberg, Germany; New York, NY, USA, 2007.

6. Nacer, A. Etude et conception de structures à base de métamatériaux pour application aux circuits microondes et antennes. Ph.D. Thesis, University of Tlemcen, Tlemcen, Algeria, 22 December 2018.

7. Bilotti, F.; Toscano, A.; Vegni, L. Design of Spiral and Multiple Split-Ring Resonators for the Realization of Miniaturized Metamaterial Samples. IEEE Trans. Antennas Propag. 2007, 55, 2258-2267. [CrossRef]

8. Sahu, B.; Tripathi, P.; Singh, R.; Singh, S.P. Dual segment rectangular dielectric resonator antenna with metamaterial for improvement of bandwidth and gain. Int. J. RF Microw. Comput.-Aided Eng. 2014, 24, 646-655. [CrossRef]

9. Bait-Suwailam, M.M.; Siddiqui, O.F.; Ramahi, O.M. Mutual Coupling Reduction Between Microstrip Patch Antennas Using Slotted-Complementary Split-Ring Resonators. IEEE Antennas Wirel. Propag. Lett. 2010, 9, 876-878. [CrossRef]

10. Balanis, C.A. Antenna Theory Analysis and Design; Arizona State University: Tempe, AZ, USA, 2005.

11. Bahl, I.J.; Bhartia, P. Microstrip Antennas; Artech House: Norwood, MA, USA, 1980.

12. Balanis, C.A. Advanced Engineering Electromagnetics; John Wiley \& Sons: New York, NY, USA, 1989. 